\title{
Hubungan Antara Dukungan Sosial Keluarga dengan Psychological Well-Being pada Narapidana Anak di Lapas Klas 1 Kutoarjo
}

\author{
Yehezkiel Adi Nugroho ${ }^{1}$ \\ Fakultas Psikologi Universitas Kristen Satya Wacana
}

\begin{abstract}
The research aims to knowing the relationship between social support and psychological well-being in child prisoner. This research is designed by using sampling saturated technique with 53 participants. Variabel of family social support using Cutrona's theory (1987) which consist of 24 items and psychological well-being variabel using Ryff's theory (1989) which consists of 42 items. The research method in data collecyion using scale method. That is the scale of family social support and the Ryff's psychological well-being scale. Data analysis using the product moment correlation analysis techniques and obtained a comparison coefficient of 0,688 with a sig value. $=0,000(p<0,001)$. Based on the research result shows a positive relationship between family social support and psychological well-being on child prisoner in prison in kutoarjo.
\end{abstract}

KEYWORDS Child prisoner, family social support, psychological well-being

CITATION Nugroho, Adi Yehezkiel. (2019). Hubungan antara dukungan sosial keluarga dengan psychological well-being pada narapidana anak di lapas klas 1 kutoarjo. Cognicia, 7, (4). 465-474.

Manusia adalah makhluk Tuhan yang paling sempurna, kesempurnaan tersebut ditandai dengan adanya akal dan budi (Salim \& Salim, 1991). Selain akal dan budi, manusia juga dibekali nafsu. Dalam paradigma psikoanalisis, Freud (2006) menyatakan bahwa nafsu berorientasi pada kenikmatan yang menuntut untuk dipenuhi. Berasal dari titik ini, manusia memiliki kebutuhan, seperti kebutuhan biologis dan seksual. Berbekal akal, manusia dapat mencari segala cara untuk memenuhi kebutuhannya, baik dengan cara yang positif maupun negatif. Tingkah laku kriminalitas dapat dilakukan oleh siapa saja, baik pria atau wanita, dan dapat berlangsung pada usia anak-anak, remaja, dewasa, bahkan lanjut usia (Kartono, 2014).

Tujuan didirikannya Lembaga Pemasyarakatan Klas I Kutoarjo antara lain adalah membentuk warga binaan pemasyarakatan (anak didik) agar menjadi manusia seutuhnya, menyadari kesalahan, memperbaiki diri, dan tidak mengulangi tindak pidana sehingga dapat diterima kembali oleh lingkungan masyarakat, berperan aktif dalam pembangunan, dan hidup secara wajar sebagai warga bertanggungjawab. Selain itu, tujuan lainnya adalah memberikan jaminan perlindungan hak asasi tahanan, narapidana (napi), dan warga binaan pemasyarakatan atau anak didik dalam rangka memperlancar proses pembinaan dan pembimbingan. Program pembinaan dan 
pembimbingan yang diberikan kepada anak didik dilakukan oleh petugas-petugas yang bertugas di lembaga pembinaan, yaitu wali.

Wali merupakan merupakan petugas lembaga pembinaan yang diberikan tugas tambahan sebagai orang tua pengganti selama anak didik dibina dalam lembaga binaan. Mereka juga mendampingi segala kegiatan yang dilakukan dan membantu anak didik ketika mengalami masalah. Setiap wali ditugaskan untuk mendampingi sekitar 8 sampai 10 anak, di mana tugas seorang wali adalah membantu mereka mengatasi segala permasalahan yang dialami di lembaga pembinaan khusus. Hampir keseluruhan petugas, khususnya wali, yang bekerja di lembaga pembinaan khusus anak ini tidak memiliki latar belakang pendidikan psikologi. Wali juga menjaga jarak dengan anak didik untuk menjaga kewibawaan sehingga kedekatan mereka cenderung kurang. Hal ini juga dilakukan supaya anak didik tunduk terhadap perintah dan peraturan yang ada.

Di Indonesia terdapat tujuh belas lembaga pembinaan khusus anak. Pada Provinsi Jawa Tengah dan Daerah Istimewa Yogyakarta, terdapat satu lembaga pemasyarakatan anak yakni Lembaga Pembinaan Khusus Anak Klas I Kutoarjo yang terletak di Kabupaten Purworejo. Lokasi lembaga pemasyarakatan ini pun strategis dengan keadaan lingkungan dan fasilitas yang cukup baik. Pembinaan yang dilakukan terhadap anak didik sebagian besar sudah sesuai dengan peraturan hukum yang berlaku di Indonesia, akan tetapi kemampuan untuk melakukan pembinaan cenderung kurang. Hubungan antara wali dan anak didik kurang harmonis. Dalam Lapas Kutoarjo, para narapidana memiliki kesejahteraan yang kurang di karenakan karena di dalam lapas tidak tersedia penjual makanan ringan ataupun minuman. Narapidana anak cenderung makan dan minum seadanya dengan menu yang sama, sehingga mereka merasa tidak sejahtera.

Menurut Undang-Undang Nomor 12 Tahun 1995 tentang Pemasyarakatan, narapidana anak adalah narapidana, anak didik pemasyarakatan, dan klien pemasyarakatan. Pasal 1-8 Undang-Undang Nomor 12 tahun 1995 tentang Pemasyarakatan menyebutkan bahwa (1) Narapidana anak adalah berdasarkan putusan pengadilan yang menjalani pidana di lapas anak paling lama sampai berumur 18 tahun, (2) Anak negara adalah berdasarkan putusan pengadilan diserahkan pada negara untuk dididik dan ditempatkan di lapas anak paling lama sampai berumur 18 tahun, (3) Anak sipil adalah anak yang atas permintaan orang tua atau walinya memperoleh penetapan pengadilan untuk dididik di lapas anak paling lama sampai berumur 18 tahun.

Pasal 1 ke 8 Undang-Undang Nomor 12 Tahun 1995 tentang Pemasyarakatan menyebutkan bahwa suatu kegiatan untuk melakukan pembinaan kepada warga binaan permayarakatan berdasarkan sistem, kelembagaan, dan cara pembinaan yang merupakan bagian akhir dari sistem pembinaan dalam peradilan pidana. Sedangkan dalam Pasal 1 ke 3, disebutkan bahwa lembaga permayarakatan yang selanjutnya disebut lapas adalah pranata untuk melaksanakan pembinaan narapidana dan anak didik pemasyarakatan. Kasus yang ada pada Lapas Khusus Anak Kutoarjo terdiri dari pencurian, tindak asusila, penganiayaan, narkoba, dan minuman keras. 
Melihat masalah-masalah yang potensial, seperti yang sudah dipaparkan di atas, maka perlu diperoleh suatu cara untuk mencegah atau mengurangi beban dari masalah tersebut. Untuk mempertahankan harapan hidup pada narapidana anak, salah satu cara yang dapat dilakukan adalah dengan mencapai Psychological Well-Being (PWB) yang optimal. Psychological Well-Being merupakan suatu kondisi psikologis individu sehat yang ditandai dengan berfungsinya aspek-aspek psikologis positif dalam proses mencapai aktualisasi diri.

Psychological Well-Being penting untuk dilakukan karena nilai positif dari kesehatan mental yang ada di dalamnya membuat seseorang dapat mengidentifikasi apa yang hilang dalam hidupnya (Ryff, dalam Compton, 2005). Psychological Well-Being, menurut Ryff (1989), adalah sebuah istilah yang dapat digunakan untuk menggambarkan kesehatan psikologis individu sesuai dengan pemenuhan kriteria fungsi psikologi positif. Ryff (1989) juga menyatakan aspek dari Psychological WellBeing di antaranya yaitu penerimaan diri (self acceptance), hubungan positif dengan orang lain (positive relationship with other), otonomi (autonomy), penguasaan lingkungan (environmental mastery), tujuan hidup (purpose in life), dan pertumbuhan pribadi (personal growth).

Dari informasi tersebut, dapat dijelaskan lebih lanjut bahwa penerimaan diri merupakan aktualisasi diri yang baik, menuju pada kematangan individu dan pemfungsian diri yang optimal. Hubungan positif dengan orang lain artinya kemampuan untuk membangun hubungan yang dekat dan hangat dengan orang lain serta adanya kontak dan hubungan sosial yang memuaskan (Keyes \& Waterman, 2003). Dampak PWB terhadap narapidana anak menunjukan pentingnya Psychological WellBeing yang tinggi untuk dimiliki. Tanpa Psychological Well-Being yang tinggi, anak akan cenderung memiliki kesehatan fisik yang buruk, tidak produktif, dan pada akhirnya menjadi beban pada keluarga mereka. Oleh karenanya, merupakan hal yang sangat penting untuk mengetahui faktor yang memengaruhi pembentukan Psychological WellBeing narapidana anak. Berbagai penelitian mengenai Psychological Well-Being telah banyak dilakukan dan dapat diketahui bahwa terdapat perbedaan faktor yang memengaruhi Psychological Well-Being seseorang.

Adapun faktor-faktor yang memengaruhi Psychological Well-Being menurut Ryff \& Keyes (1995), antara lain usia, jenis kelamin, status sosial ekonomi, dukungan sosial, religiusitas, dan kepribadian. Weiss (dalam Cutrona, 1994) mendefinisikan bahwa dukungan sosial adalah pertukaran interpersonal di mana salah seorang memberikan bantuan atau pertolongan kepada orang lain. Keberadaan keluarga dan jaringan sosial yang memberikan dukungan sosial menunjukan kontribusi terhadap peningkatan Psychological Well-Being (Litwin,2006). Dukungan ini dapat berasal dari berbagai sumber, di antaranya orang yang dicintai seperti orang tua, pasangan, anak, teman, dan kontak sosial dengan masyarakat (Rietschlin, dalam Taylor, 2009).

Weiss (dalam Cutrona, 1994) mengemukakan adanya enam komponen dukungan sosial yang disebut sebagai "The Social Provision Scale". Masing-masing komponen dapat berdiri sendiri, namun saling berhubungan. Komponen tersebut adalah Reliable alliance (ketergantungan yang dapat diandalkan), guidance (bimbingan), reassurance of worth (pengakuan positif), emotional attachment (kedekatan emosional), 
social integration (integrasi sosial), dan opportunity to provide nurturance (kesempatan untuk mengasuh).

Hubungan dukungan sosial keluarga dengan Psychological Well-Being pada narapidana anak di Lapas Kutoarjo adalah saat keluarga membesuk narapidana anak pada jadwal yang sudah diberikan oleh pihak lapas, yaitu hari Jumat dari jam 10.0012.00 WIB. Saat dibesuk, narapidana anak mendapatkan dukungan dari keluarga seperti nasihat dan penguatan positif agar dirinya dapat menjalani masa pidana/ \pembinaan dengan baik. Narapidana anak juga mendapat berbagai hal yang tidak disediakan pihak lapas dari keluarnya. Ketika mereka mendapat dukungan social yang tinggi, maka akan berpengaruh pada Psycohological-Well-Being. Penelitian yang dilakukan oleh Millatina dan Yanuvianti (2014) menunjukan hasil hubungan positif terhadap dukungan sosial dengan Psychological Well-Being. Namun, penelitian yang dilakukan oleh Sari dan Suprapti (2013) tentang pengaruh dukungan sosial keluarga terhadap Psychological Well-Being pada masa pension menunjukan hasil yang berbeda, yakni tidak terdapat pengaruh antara dukungan keluarga dengan psychological Well-Being pada masa pensiun.

Berdasarkan fenomena dan pro-kontra penelitian di atas, peneliti merasa tertarik untuk melakukan penelitian mengenai "Hubungan antara Dukungan Sosial Keluarga dengan Psychological Well-Being pada Narapidana Anak di Lapas Kutoarjo". Hipotesis dalam penelitian ini adalah "Ada hubungan positif antara dukungan sosial keluarga dan Psychological Well-Being pada Narapidana Anak di Lapas Kutoarjo". Semakin tinggi tingkat dukungan sosialnya maka akan semakin tinggi Psychological Well-Being dan semakin rendah tingkat dukungan sosialnya maka akan semakin rendah juga tingkat Psychological Well-Being-nya.

\section{METODE PENELITIAN}

Penelitian ini menggunakan metode kuantitatif jenis korelasional. Penelitian korelasional, menurut Fraenkel dan Wallen (2008) adalah suatu penelitian yang digunakan untuk mengetahui hubungan dan tingkatan hubungan antara dua variabel atau lebih tanpa ada upaya untuk memengaruhi variabel tersebut, sehingga tidak terdapat manipulasi variabel. Adapun penerapan penelitian korelasional pada penelitian ini digunakan untuk mengetahui hubungan dukungan sosial dengan psychological well-being pada narapidana anak.

Penelitian ini terdiri dari masing-masing satu variabel bebas dan terikat. Variabel bebasnya adalah dukungan sosial keluarga, yakni suatu bentuk tingkah laku seseorang yang dapat menumbuhkan perasaan nyaman dan membuat individu percaya bahwa ia dihormati, dihargai, dicintai, dan bahwa orang lain baik individu, kelompok maupun masyarakat luas bersedia memberikan perhatian dan keamanan kepada dirinya. Dalam penelitian ini, komponen-komponen dukungan sosial yang diukur adalah yang dikemukakan oleh Weiss (dalam Cutrona dkk, 1994), yaitu komponen instrumental support yang terdiri dari reliavel alliance dan guidance dan komponen emotional support yang terdiri dari reassurance of worth, attachment, sosial integration, dan opportunity to provide nurturance. 
Variabel terikat dalam penelitian ini adalah psychological well-being, yang mencakup mencakup kemampuan individu untuk menerima dirinya apa adanya (selfacceptance), membentuk hubungan yang hangat dengan orang lain (positive relation with others), memiliki kemandirian dalam menghadapi tekanan sosial (autonomy), mengontrol lingkungan eksternal (environmental mastery), memiliki tujuan dalam hidupnya (purpose in life), serta mampu merealisasikan potensi dirinya secara continue (personal growth) (Ryfff, 1989).

Partisipan adalah narapidana anak Lembaga Pembinaan Khusus Anak Klas 1 Kutoarjo yang tergolong dalam kategori remaja awal, atau dalam kisaran usia 12-15 tahun (Soetjiningsih, 2012). Kriteria kedua adalah sedang menjalani pembinaan di Lembaga Pembinaan Khusus Anak Klas 1 Kutoarjo. Teknik pengumpulan data menggunakan sampling purposive. Maka, peneliti menetapkan subjek yang menjadi sampel penelitian sebanyak 53 orang.

Metode pengumpulan data pada penelitian ini dengan menggunakan kuesioner. Kuesioner merupakan sejumlah pernyataan tertulis yang digunakan untuk memperoleh informasi dari responden, dalam arti laporan digunakan tentang pribadi atau hal-hal yang diketahui (Arikunto, 2006:128). Berikut penjabaran dari masingmasing kuesioner.

1. Skala Dukungan Sosial Keluarga

Variabel dukungan sosial keluarga dalam penelitian ini diukur menggunakan alat ukur social provisions scale yang dikembangkan oleh Cutrona (1994). Dalam alat ukur tersebut, terdapat 24 item yang masing-masing aspeknya ditambah oleh peneliti menjadi 31 item berdasarkan 6 komponen, yaitu instrumental support yang terdiri dari reliabel alliance dan guidance dan komponen emotional support yang terdiri dari reassurance of worth, attachment, social integration, dan opportunity to provide nurturance. Skala dirancang menggunakan metode skala Likert dengan 4 kategori pilihan jawaban, yaitu Sangat Setuju (SS), Setuju (S), Tidak Setuju (TS), dan Sangat Tidak Setuju (STS). Hasil perhitungan melalui program SPSS menunjukkan bahwa item yang gugur sejumlah 7 buah, sedangkan sisa item yang memiliki daya diskriminasi baik dengan rentang 0,253 sampai dengan 0,644 sesuai dengan batas koefisien item $\geq 0,25$ ( Azwar, 2004). Nilai $\alpha$ yang diperoleh adalah 0,886 yang berarti sangat reliabel.

Reliability Statistics

\begin{tabular}{|c|c|c|}
\hline \multicolumn{3}{|c|}{ Cronbach's Alpha Based on Standardized } \\
\hline Cronbach's Alpha & Items & $\mathrm{N}$ of Items \\
\hline .886 & .882 & 24 \\
\hline
\end{tabular}

2. Skala Psychological Well-Being

Variabel psychological well-being diukur menggunakan alat ukur Ryff scale. Alat ukur tersebut berisi 42 item dari masing-masing aspek yang dikembangkan oleh Ryff (1989) berdasarkan aspek-aspek psychological well-being, yaitu selfacceptance, positive relation with other, autonomy, environmental mastery, purpose in life, dan personal growth. Skala dirancang menggunakan metode skala Likert dengan 4 kategori pilihan jawaban yaitu Sangat Setuju (SS), Setuju (S), Tidak Setuju (TS), 
dan Sangat Tidak Setuju (STS). Dari hasil perhitungan melalui program SPSS, item yang gugur sejumlah 23 item sedangkan sisa item yang memiliki daya diskriminasi baik di atas 0,25 (Azwar, 2004) adalah sebanyak 25 item, dengan rentang $0,267-0,626$ sehingga nilai $\alpha$ yang diperoleh adalah 0,872 yang berarti sangat reliabel.

\begin{tabular}{ccc}
\multicolumn{3}{c}{ Reliability Statistics } \\
\hline \multicolumn{3}{c}{ Cronbach's } \\
Alpha Based \\
on \\
Cronbach's & Standardized \\
Alpha & Items & N of Items \\
\hline .872 & .867 & 25 \\
\hline
\end{tabular}

Teknik analisis data yang digunakan untuk mengetahui hubungan antara dukungan sosial keluarga dengan psychological well-being pada narapidana anak di Lapas Klas 1 Kutoarjo adalah korelasi product moment dengan menggunakan bantuan program SPSS versi 26.0.

\section{HASIL PENELITIAN}

Kategori dibagi menjadi 4, yaitu sangat tinggi, tinggi, rendah, dan sangat rendah. Pembagian interval dilakukan dengan mengurangi jumlah skor tertinggi dengan skor terendah dan membaginya dengan jumlah kategori.

$$
\boldsymbol{i}=\frac{\text { skor tertinggi-skor terendah }}{\text { jumlah kategori }}
$$

Dari perhitungan memakai rumus tersebut, maka didapatkan hasil seperti pada table di bawah ini:

Table Dukungan Sosial Keluarga

\begin{tabular}{cccccc}
\hline Kategori & Interval & Frekuensi & Persentase & Mean & SD \\
\hline $\begin{array}{c}\text { Sangat } \\
\text { tinggi }\end{array}$ & $78 \leq \mathrm{x}<96$ & 24 & $45 \%$ & & \\
$\begin{array}{c}\text { Tinggi } \\
60 \leq \mathrm{x}<78\end{array}$ & 25 & $47 \%$ & 73.87 & 10.33 \\
$\begin{array}{c}\text { Rendah } \\
\begin{array}{c}\text { Sangat } \\
\text { rendah }\end{array}\end{array}$ & $24 \leq \mathrm{x}<60$ & 4 & $8 \%$ & & \\
\hline & $\mathrm{N}$ & 0 & $0 \%$ & & \\
\hline
\end{tabular}

Dari data di atas, dapat ditarik kesimpulan bahwa tingkat dukungan sosial keluarga terhadap 53 partisipan menunjukan kategori yang bervariasi, mulai dari kategori sangat tinggi dengan persentase $45 \%$, kategori tinggi sebanyak $47 \%$, kategori rendah sebanyak $8 \%$, dan kategori sangat rendah sebanyak $0 \%$, Mean yang diperoleh adalah 73,87 dengan standar deviasi sebesar 10,33. Berdasarkan mean dan standar 
deviasi, maka dukungan sosial yang dimiliki narapidana anak berada pada kategori tinggi.

Table Psychological well-being

\begin{tabular}{cccccc}
\hline Kategori & Interval & Frekuensi & Persentase & Mean & SD \\
\hline $\begin{array}{c}\text { Sangat } \\
\text { tinggi }\end{array}$ & $81,25 \leq x<100$ & 16 & $30 \%$ & & \\
$\begin{array}{c}\text { Tinggi } \\
\text { Rendah }\end{array}$ & $62,5 \leq x<81,25$ & 31 & $58 \%$ & 74.70 & 9.44 \\
$\begin{array}{c}\text { Sangat } \\
\text { rendah }\end{array}$ & $25 \quad \leq x<62,5$ & 6 & $11 \%$ & & \\
\hline
\end{tabular}

53

Dari data di atas dapat ditarik kesimpulan bahwa tingkat psychological wellbeing terhadap 53 narapidana anak di Lapas Kutoarjo menunjukan kategori yang bervariasi, mulai dari kategori sangat tinggi dengan persentase 30\%, kategori tinggi $58 \%$, kategori rendah $11 \%$, dan sangat trendah $0 \%$. Mean yang diperoleh adalah 74,70 dengan standar deviasi sebesar 9,44. Berdasarkan mean dan standar deviasi, maka psychological well-being yang dimiliki oleh narapidana anak di Lapas Kutoarjo berada pada kategori sangat tinggi.

Pada tabel di bawah terdapat hasil uji normalitas dengan Kolmogorov- Smirnov Test. Variabel dukungan sosial keluarga memiliki nilai signifikansi sebesar 0,731 ( $\mathrm{p}>$ $0,05)$. Hasil dari variabel psychological well-being memiliki nilai signifikasi sebesar 0,964 $(\mathrm{p}>0,05)$.

One-Sample Kolmogorov-Smirnov Test

\begin{tabular}{llll}
\hline & & DKS & PWB \\
\hline $\mathrm{N}$ & & 53 & 53 \\
Normal Parameters $^{\mathrm{a}}$ & Mean & 73.8679 & 74.6981 \\
& Std. Deviation & 10.32554 & 9.43517 \\
Most Extreme & Absolute & .095 & .069 \\
Differences & Positive & .095 & .046 \\
& Negative & -.089 & -.069 \\
Kolmogorov-Smirnov Z Z & .688 & .500 \\
Asymp. Sig. (2-tailed) & & .731 & .964 \\
\hline
\end{tabular}

a. Test distribution is Normal.

Pengujian linearitas pada variabel dukungan sosial keluarga dan psychological well-being menunjukan nilai 0,669 dengan nilai signifikan 0,846 ( $p>0,05)$. Dapat dikatakan bahwa hubungan antara dukungan sosial dengan Psychological Well-Being adalah sejajar atau linear.

\section{ANOVA Table}




\begin{tabular}{|c|c|c|c|c|c|c|c|}
\hline & & & $\begin{array}{l}\text { Sum of } \\
\text { Squares }\end{array}$ & $\mathrm{df}$ & $\begin{array}{l}\text { Mean } \\
\text { Square }\end{array}$ & $\mathrm{F}$ & Sig. \\
\hline \multirow[t]{5}{*}{$Y^{*} X$} & Between & (Combined) & 3332.753 & 30 & 111.092 & 1.885 & .064 \\
\hline & Groups & Linearity & 2189.268 & 1 & 2189.268 & 37.152 & .000 \\
\hline & & $\begin{array}{l}\text { Deviation from } \\
\text { Linearity }\end{array}$ & 1143.485 & 29 & 39.431 & .669 & .846 \\
\hline & Within Groups & & 1296.417 & 22 & 58.928 & & \\
\hline & Total & & 4629.170 & 52 & & & \\
\hline
\end{tabular}

Hubungan antara kedua variabel tersebut dihitung menggunakan uji korelasi product moment-pearson. Hasil yang didapat adalah nilai koefisien korelasi sebesar $\mathrm{r}=$ 0,688 dengan signifikansi sebesar 0,000 ( $\mathrm{p}<0,05)$ bahwa terdapat hubungan positif antara dukungan sosial keluarga dengan psychological well-being pada narapidana anak di Lapas Kutoarjo. Hasil pengujian hipotesis tersebut dapat dilihat pada tabel di bawah ini.

\begin{tabular}{lll}
\multicolumn{2}{c}{ Correlations } \\
\hline & \multicolumn{1}{c}{$\mathrm{X}$} & $\mathrm{Y}$ \\
\hline Pearson & 1 & $.688^{* *}$ \\
Correlation & & .000 \\
Sig. (1-tailed) & & 53 \\
$\mathrm{~N}$ & 53 & 1 \\
\hline Pearson & $.688^{* *}$ & \\
Correlation & .000 & \\
Sig. (1-tailed) & 53 & 53 \\
$\mathrm{~N}$ & 53 \\
\hline
\end{tabular}

**. Correlation is significant at the 0.01 level (1tailed).

\section{DISKUSI}

Berdasarkan hasil penelitian, diperoleh hasil nilai koefisien korelasi sebesar $r=$ 0,688 dengan signifikansi sebesar 0,000 ( $p>0,05)$ yang berarti ada hubungan positif antara dukungan sosial keluarga dengan psychological well-being pada narapidana anak di Lapas Kutoarjo, sehingga hipotesis yang diajukan dalam penelitian ini dapat diterima. Narapidana anak memiliki dukungan sosial keluarga paling banyak dalam kategori tinggi sebanyak $47 \%$, sedangkan persentase dari psychological well-being adalah sebanyak 58\%. Hal ini didukung dengan penelitian yang dilakukan oleh Millatina dan Yanuvianti (2014) bahwa terlihat jelas kualitas dukungan sosial memengaruhi tingkat psychological well-being. 
Amawidyati dan Utami (2007) mengungkapkan bahwa sikap positif seperti ketabahan, adanya penerimaan, serta hubungan yang positif dengan orang lain dapat menyebabkan terbentuknya kondisi psikologis yang positif. Hal ini dapat ditinjau pada fenomena di lapangan, narapidana anak merasa lebih banyak belajar dari masa lalunya. Kesalahan masa lalu membuat ia mengerti apa yang harus dibenahi di masa depan. Ketika berada di dalam penjara, narapidana juga merasa senang karena mengenal orang-orang baru dan mempunyai hubungan yang baik di dalam panti. Mereka mempunyai wadah untuk bercerita tentang masalah pribadi sehingga ada penguatan positif dari orang sekitar yang membuat para narapidana menjadi tabah dalam menjalani ujian hidup.

Dukungan sosial merupakan keberadaan orang lain yang dapat diandalkan untuk memberi bantuan, semangat, penerimaan, dan perhatian untuk meningkatkan kesejahteraan atau kualitas hidup bagi individu yang bersangkutan (Jhonson \& Jhonson, 1991). Teori ini memperkuat fenomena yang terdapat di lapangan yang menunjukan adanya peningkatan psychological well-being dari para narapidana anak yang mendapat kunjungan keluarga. Kehadiran seseorang yang membesuknya membuat para narapidana merasa senang. Terlebih ketika yang datang adalah keluarga, mereka mendapatkan sesuatu yang meningkatkan rasa senang, seperti uang saku, perlengkapan mandi, dan makanan.

Menurut Rathi dan Rastogi (2007), stres merupakan salah satu faktor yang dapat memengaruhi tinggi-rendahnya psychological well-being pada diri seseorang. Teori ini juga sejalan dengan penelitian yang dilakukan oleh Yasin dan Dzulkifli (2010), bahwa kurangnya dukungan sosial menjadi salah satu faktor yang menyebabkan masalah psikologis. Setiap dimensi dalam dukungan sosial memiliki peran masingmasing yang dapat memengaruhi psychological well-being pada narapidana anak di Lapas Kutoarjo. Dukungan sosial memberikan sumbangan efektif terhadap psychological well-being sebesar 47,33\% yang artinya masih terdapat faktor-faktor lain yang memengaruhi, seperti usia, jenis kelamin, sosio ekonomi, religiusitas, dan kepribadian.

\section{SIMPULAN DAN IMPLIKASI}

Berdasarkan hasil penelitian yang sudah diuraikan, maka dapat ditarik beberapa kesimpulan yakni terdapat hubungan positif yang signifikan antara variabel dukungan sosial dengan psychological well-being pada narapidana anak di Lapas Kutoarjo. Semakin tinggi dukungan sosial keluarga maka semakin tinggi pula tingkat psychological well-being, begitu juga sebaliknya. Narapidana anak memiliki dukungan sosial keluarga paling banyak dalam kategori tinggi sebanyak 57\%, sedangkan persentase psychological well-being pada kategori tinggi adalah $51 \%$.

Implikasi penelitian ini untuk lapas adalah semoga dapat menambahkan bidang konseling supaya narapidana bisa mendapatkan pembinaan mental dan menemukan tujuan hidupnya. Adapun bagi narapidana, disarankan untuk melakukan hal-hal positif agar dapat menjadi introspeksi diri supaya kelak tidak mengulangi kejahatan yang sama. Bagi peneliti selanjutnya, disarankan untuk meneliti faktorfaktor lain yang mempengaruhi psychological well-being mengingat penelitian ini juga memiliki banyak keterbatasan. 


\section{REFERENSI}

Amawidyati, S. A. G.\& Utami, M. S. (2007). Religiusitas dan psychological well being pada korban gempa. Jurnal Psikologi Universitas Gajah Mada, 34, 164-176. DOI: 10.22146/jpsi.7095

Azwar, S. 2004. Validitas dan reliabilitas. Yogyakarta: Pustaka Pelajar.

Cutrona, C. E, et. Al. (1994). Peceived parental social support and academic achievement : an attachment theory perspective. Journal of Personality and Social Psychology. 66(2), 369378

Johnson, D. W. \& Jhonson, F.P. (1991). Joining Together: Group Theory and Group Skills. Fourth Edition. London: Prentice Hall International

Kartono, K. (2014). Patologi sosial. Jakarta: Rajawali.

Keyes, C. L. M., \& Waterman, M. B. (2003). Dimensions of Well-Being and Mental Health In Adulthood-En M. Bornstein, L. Davidson, CLM Keyes y K. Moore (eds.), Well-being: Positive Development Throughout the Life Course (pp. 447-497).

Lubis, S.M., \& Maslihah, S. (2012). Analisis sumber-sumber kebermaknaan hidup narapidana yang menjalani hukuman seumur hidup. Jurnal Psikologi Universitas Diponegoro,11(1), 28-39.

Millatina, A. dan Yanuvianti, M. 2015. Hubungan antara Dukungan Sosial dengan Psyhological Well-Being pada Wanita Menaupose (di RS Harapan Bunda Bandung). http://karyailmiah.unisba.ac.id/index.php/psikologi/article/view/1250

Ryff, C. D. (1989). Happines is everything, or is it? Explorations on the meaning of Psychological Well-Being. Journal of personality and Social Psychology, 57, 1069-1081. DOI: 10.1037/0022-3514.57.6.1069

Ryff, C. D., \& Keyes, C. L. (1995). The structure of psychological well-being revisited. Journal of Personality and Social Psychology, 69, 719-727. DOI: 10.1037/0022-3514.09.4.719

Ryff, C. D., \& Singer, B. H. (2006). Best news yet on the six-factor model of well-being. Social Science Research, 35(4), 1103-1119.

Sari, D., \& Suprapti, V. (2013). Pengaruh dukungan sosial keluarga terhadap Psychological well-being pada masa pensiun. Jurnal Psikologi Pendidikan Dan Perkembangan 2

Sarafino,E.P. (1998). Health Psychology : Biopsychososial Interactions. Third Edition. United States of American : John Wiley \& Sons. Inc

Soetjiningsih, Christiana Hari. (2012). Perkembangan Anak sejak Pembuahan sampai denganAnak-anak Akhir. Jakarta: Prenada Media Group

Yasin, Safree, A., \& Dzulkifli, M. A., (2010). The relationship between social support and psychological problems among students. 